\title{
Natureza transindividual dos direitos difusos e coletivos e as suas implicações jurídicas quanto à titularidade e às formas de defesa dos interesses de seus titulares
}

Transindividual nature of diffuse and collective rights and its legal implications regarding title and defense of the interests of its owners

Washington Eduardo Perozim da Silva Universidade Metodista de Piracicaba, Piracicaba, São Paulo, Brasil

Resumo O presente artigo tem por objetivo discorrer acerca da natureza transindividual dos direitos fundamentais difusos e coletivos e as suas implicações jurídicas quanto à titularidade e às formas de defesa desses interesses. Para tanto, além de se estudar as definições doutrinárias, serão apresentados os principais fatos históricos que levaram à previsão dessa modalidade normativa nos ordenamentos dos países democráticos, em especial no Brasil, e se analisará a "teoria das gerações” desenvolvida por Karel Vasak; e também se discorrerá sobre a dificuldade para a identificação do titular de tais direitos, bem como, a importância da participação do Estado e dos órgãos de representação de classe na defesa de tais interesses. Em seguida, serão apresentadas as principais ações realizadas pelo Estado, partidos políticos e entidades de classe para se garantir, não só a defesa, mas também a concretização desses direitos. Logicamente, o presente trabalho não almeja, nem poderia, trazer novas definições ou pontos de vista distintos daqueles já consolidados pela doutrina, mas apenas contribuir com as discussões existentes sobre o tema, já que em decorrência das grandes transformações sociais que despontam no horizonte, torna-se imprescindível 
desenvolver novas ferramentas jurídicas para se resguardar a segurança dos cidadãos brasileiros.

Palavras-chave: Direitos fundamentais. Direitos difusos e coletivos. NATUREZA TRANSINDIVIDUAL.

Abstract The purpose of this article is to discuss the transindividual nature of diffuse and collective fundamental rights and their legal implications as to the ownership and forms of defense of these interests. Therefore, in addition to studying the doctrinal definitions, we will present the main historical facts that led to the prediction of this normative modality in the democratic countries, especially in Brazil, to analyze the "theory of generations" developed by Karel Vasak; It will be discussed on the difficulty to identify the holder of such rights, as well, as the importance of the participation of the State and the representative organs of class in the defense of such interests. The main actions carried out by the State, political parties and class entities will be presented in order to guarantee, not only the defense, but also the realization of these rights.Logically, the present work does not seek and could not bring new definitions or points of view different from those already consolidated by the doctrine, but only to contribute to the existing discussions on the subject, since, due to the great social transformations that emerge on the horizon, it becomes imperative to develop new legal tools to safeguard the security of Brazilian citizens.

Key-words: Fundamental Rights. Diffuse and COllective Rights. TRANSINDIVIDUAL NATURE.

\section{INTRODUÇÃO}

O legislador brasileiro, seguindo uma forte tendência europeia - adotada, principalmente, após o final da Segunda Guerra Mundial -, inseriu na atual Constituição Federal inúmeras normas de direito fundamental.

A maioria dos doutrinadores destaca que tais direitos não foram concentrados apenas em um só artigo, mas, sim, espalhados por todo o 
texto constitucional, citando como exemplo o "direito ao meio ambiente" (art. 225), o "direito à cultura" (art. 215), contudo, o exegeta poderá encontrá-los, de forma mais evidente, no Título II (Direitos e garantias individuais) e seus respectivos capítulos I (art. $5^{\circ}$. [direitos e garantias fundamentais]) e II (artigos, $6^{\circ}$. e $7^{\circ}$. [direitos sociais]).

De igual modo, a atenta análise do catálogo desses direitos comprovará que o legislador constituinte não pretendeu proteger somente os de "caráter individual" (vida, liberdade, privacidade etc.), mas, também, aqueles de "natureza transindividual", considerados pela doutrina como "direitos fundamentais da terceira dimensão".

Sem sombra de dúvidas, a proteção desses direitos transindividuais se fazia necessária, uma vez que na sociedade hodierna são inúmeras as relações fáticas e jurídicas cujo titular de tais direitos não poderia ser identificado de forma individualizada e, que a defesa desses interesses (difusos e coletivos) somente poderia ocorrer mediante a intervenção direta do próprio Estado ou por meio de órgãos representantes de classe.

Todavia, essa característica peculiar - a transindividualidade - implica uma série de tratamentos jurídicos distintos daqueles conferidos aos direitos fundamentais das duas primeiras dimensões, já que, tanto a "questão da titularidade" quanto a da "representação dos interesses dos titulares" geram diversas repercussões e questionamentos entre os juristas e demais operadores do direito.

Assim, este trabalho tem por objetivo discorrer sobre a natureza transindividual dos direitos fundamentais difusos e coletivos e as suas implicações jurídicas quanto à "titularidade" e às "formas de defesa dos interesses de seus titulares" por parte do Estado e pelos órgãos representantes de classe.

\section{CONCEITO, OBJETIVO, FUNÇÃo E PRINCIPAL FUNDAMENTO AXIO- LÓGICO DOS DIREITOS FUNDAMENTAIS}

Para se alcançar a pretensão desta obra, é imprescindível dissertar, mesmo que rapidamente, sobre o conceito, o objeto e a função dos direitos fundamentais.

Konrad Hesse (2013, p. 33-34), quando discorreu sobre essa modalidade normativa, afirmou que os principais objetivos desses direitos 
eram o de assegurar a liberdade e a dignidade humana de todos os cidadãos:

Os direitos fundamentais devem criar e manter condições elementares para assegurar uma vida em liberdade e dignidade humana. Isso só se consegue quando a liberdade da vida em sociedade resulta garantia em igual medida que a liberdade individual.

(...)

Essas circunstâncias forjam a singularidade, a estrutura e a função dos direitos fundamentais: garantem não só os direitos subjetivos dos indivíduos, mas também princípios objetivos básicos para o ordenamento constitucional democrático e do Estado de Direito, fundamentos do Estado constituído pelos direitos e ordenamento jurídico.

Luigi Ferrajoli (2009, p. 19) os definiu como direitos subjetivos de todos os seres humanos, como pessoas, cidadãos ou pessoa com capacidade para trabalhar:

(...) son 'derechos fundamentales' todos aquellos derechos subjetivos que corresponden universalmente a 'todos' los seres humanos em cuanto dotados del status de personas, de cidadanos o personas com capacidad para obrar; entendendo por 'derecho subjetivo' cualquier expectativa positiva (de prestaciones) o negativa (de no sufrir lesiones) adscricta a um sujeto, prevista asimismo por uma norma jurídica positiva, como pressuposto de su idoneidade para ser titular de situaciones jurídicas y/o autor de los actos que son ejericido de éstas.

Joaquim Gomes Canotilho (2002, p. 405), ao discorrer sobre o tema, afirma que os direitos fundamentos cumprem a função de direitos de defesa dos cidadãos sob uma dupla perspectiva:

(...) [1] constituem, num plano jurídico-objetivo, normas de competência negativa para os poderes públicos, 
proibindo fundamentalmente as ingerências destes na esfera jurídica individual [2] implicam, num plano jurídico-subjetivo, o poder de exercer positivamente direitos fundamentais (liberdades positivas) e de exigir omissões dos poderes públicos, de forma a evitar agressões lesivas por parte dos mesmos (liberdade negativa).

George Marmelstein (2016, p. 18), por sua vez, afirma que são normas jurídicas intimamente ligadas ao princípio da dignidade da pessoa humana, estabelecidas na lei maior de uma nação que, não só fundamentam, mas legitimam todo o ordenamento jurídico:

Os direitos fundamentais normas jurídicas intimamente ligadas à ideia de dignidade da pessoa humana e de limitação do poder, positivadas no plano constitucional de determinado Estado Democrático de Direito, que, por sua importância axiológica, fundamentam e legitimam todo o ordenamento jurídico.

Conforme se constata, nos posicionamentos doutrinários apresentados até aqui, pode-se encontrar certa unanimidade no que diz respeito aos objetivos dessa modalidade direitos, já que todos os autores entendem que as suas principais funções são i) a de embasar o ordenamento jurídico de um país; ii) a de garantir, através de ações omissivas ou comissivas pelo Estado, a "liberdade" e a "segurança" dos cidadãos (nacional ou estrangeiro, individual ou coletiva) e iii) a de assegurar a efetivação do princípio da dignidade da pessoa humana junto à sociedade ou à nação.

Diferente não é o entendimento do professor lusitano Jorge Reis Novais (2015, p. 73), ao reconhecer no princípio da dignidade humana o principal fundamento dos direitos fundamentais:

A dignidade da pessoa humana pode, então, ser percebida como fundamento da consagração constitucional de um elenco constitucional de direitos fundamentais destinados a assegurar a autonomia, a liberdade e uma 
vida condigna a todos os cidadãos (incluindo-se potencialmente nesse elenco de liberdade, de igualdade, de participação política e os direitos sociais), que o Estado e os poderes públicos ficam obrigados a respeitar e a observar, não enquanto liberdade, não enquanto autolimitação livremente assumida, mas enquanto vinculação jurídica, que, se o Estado pretende reivindicar para si mesmo a qualificação como Estado de Direito, não pode se isentar.

Nota-se, assim, que a dignidade humana é a principal base axiológica dos direitos fundamentais e, via de consequência, tem extrema relevância em seus objetivos e funções.

Uma vez estabelecidos o conceito, os objetivos e suas funções; sabendo-se, ainda, que o princípio da dignidade humana é o principal esteio axiológico dos direitos fundamentais, torna-se mais fácil compreender a sua evolução histórica e a classificação de suas dimensões.

\section{EVOLUÇÃo HISTÓRICA DOS DIREITOS FUNDAMENTAIS E A SUA CONSOLIDAÇÃO NO ORDENAMENTO JURÍDICO-CONSTITUCIONAL BRASILEIRO}

Apresentados o conceito, os objetivos e as funções dos direitos fundamentais, torna-se, neste momento, imprescindível que o leitor, agora, tenha conhecimento dos fatos históricos que marcaram o seu desenvolvimento e a importância que essa modalidade normativa conquistou, ao longo dos anos, junto aos ordenamentos jurídicos dos países democráticos.

Destaca-se, desde já, que os direitos que hoje são denominados "fundamentais" têm origem, ou melhor dizendo, são o produto de movimentos sociais - que não poucas vezes resultaram em guerras ou revoluções - ocorridos no curso da História, que tinham por objetivo principal i) resguardar a dignidade do ser humano e ii) a criação de um catálogo de proteções para que o indivíduo pudesse evitar possíveis abusos praticados por seus governantes. 
Sérgio Pinto Martins (2008, p. 6) disserta que o desenvolvimento dos direitos fundamentais possui intrínseca relação com a evolução da concepção de Estado, sua organização administrativa, política, ideológica e dos valores existentes em cada época:

Os direitos humanos foram evoluindo no curso da história, de acordo com a cultura de cada povo. Representam uma conquista histórica e política. São direitos históricos, mas também necessidades das pessoas no curso do tempo, que foram sendo reconhecidas. São caracterizados por lutas no sentido de obter novas liberdades. O objetivo foi obter a dignidade da pessoa humana contra opressões, tiranias, e o poder excessivo e a intervenção do Estado. Foram sendo obtidos de 'modo gradual', não todos de uma vez e nem de uma vez por todas.

Para a maioria dos historiadores, os direitos fundamentais encontram seu primeiro marco histórico, em 1215, com a redação da Carta de João Sem-Terra:

É na Inglaterra da Idade Média, mais especificamente, no século XIII, que encontramos o principal documento referido por todos que se dedicam ao estudo da evolução dos direitos humanos. Trata-se da Magna Carta Libertatum, pacto firmado em 1215 pelo Rei João Sem-Terra e pelos bispos e barões ingleses. Este documento, inobstante tenha apenas servido para garantir aos nobres ingleses alguns privilégios feudais, alijando, em princípio, a população do acesso aos 'direitos' consagrados no pacto, serviu como ponto de referência para alguns direitos e liberdades civis clássicos, tais como o habeas corpus, o devido processo legal e a garantia de propriedade (SARLET, 2015, p. 41).

Contudo, é com a revolução gloriosa (Inglaterra/1688) que os direitos fundamentais ganharam contorno no ordenamento daquele país e, por conseguinte, na História, pois, com a edição da Bill of Rigths os poderes monárquicos (estatais) sofreram inúmeras restrições. 
Como consequência dos fatos ocorridos na Europa, na América do Norte, em 1776 é promulgada a "Declaração de Direitos do Bom Povo da Virginia" e, logo em seguida, a "Constituição Norte Americana" (1787) e suas emendas (1791).

Porém, seria na França - já rendida às ideias iluministas dos pensadores da época, entre os quais se destacam François Marie Arouet (Voltaire) e Jean-Jaques Rousseau - que os direitos fundamentais seriam elevados ao status e à proteção que possuem até os dias atuais.

Foi assim que, na esteira da revolução francesa (1788), em 27.08.1789, a Assembleia Constituinte daquele país aprovou a "Declaração de Direitos do Homem e do Cidadão"; um texto, nos dizeres de José Afonso da Silva (2011, p. 158), elegante, sintético e preciso:

O texto da declaração de 1789 é de estilo lapidar, elegante, sintético, preciso e escorreito, que, em dezessete artigos, proclama os princípios da liberdade, da igualdade, da propriedade e da legalidade e as garantias individuais liberais que ainda se encontram nas declarações contemporâneas, salvas as liberdades de reunião e de associação que ela desconhecera, firmado que estava numa rigorosa concepção individualista.

Ainda no tocante ao desenvolvimento histórico, deve-se fazer referência às Constituições do México (1917) e à da República de Weimar (1919) onde, pela primeira vez, os direitos sociais - que mais tarde receberiam a denominação "direitos fundamentais da segunda dimensão" - ganharam destaque e receberam maiores cuidados de legislador constituinte.

Após as atrocidades ocorridas na Segunda Guerra Mundial, a Assembleia Geral das Nações Unidas, no dia 10.12.1948, aprovou a "Declaração Universal dos Direitos Humanos”, considerado, atualmente, o mais amplo documento criado em favor da humanidade:

A declaração de 1948 foi um marco na evolução dos direitos humanos, pois serviu de divisor entre o conteú- 
do, meramente declaratório, registrado nas declarações direitos humanos e a conquista da força normativa, com a constitucionalização desses direitos. Inúmeras Constituições do pós-guerra adotaram-na como fonte de inspiração (MUNIZ, 2010, p. 144).

Sob o lema da revolução liberal-burguesa "liberdade, igualdade e fraternidade", os direitos fundamentais se desenvolveram, acompanhando os movimentos culturais e sociais de cada época; alcançando as dimensões que possuem atualmente, sendo assegurados, praticamente, em todas as cartas constitucionais democráticas.

No ordenamento jurídico brasileiro, tal qual ocorrido no continente europeu, os direitos fundamentais foram se consolidando ao longo do tempo, sendo a Constituição Imperial (1824) a primeira a subjetivá-los e a positivá-los:

As constituições brasileiras sempre inscreveram uma declaração dos direitos do homem brasileiro e estrangeiro residente no país. Já observamos, antes, que a primeira constituição, no a subjetivar e positivar os direitos do homem, dando-lhes concreção jurídica efetiva, foi a do Império do Brasil, de 1824, anterior, portanto, à da Bélgica de 1831, a que se tem dado tal primazia (SILVA, 2011, p. 170).

Em que pese haver menção a direitos de natureza social (educação [instrução primária] e saúde) nota-se, pela leitura de seu artigo 178, a incontestável influência liberal-burguesa em relação à garantia dos direitos individuais: "A inviolabilidade dos direitos civis, e políticos dos cidadãos brasileiros, que tem por base a liberdade, a segurança individual, e a propriedade, é garantida pela Constituição, pela seguinte maneira".

A Constituição da República de 1891 assegurou maior ênfase que a anterior em relação ao liberalismo (ideal republicano da época), mantendo a garantia dos direitos fundamentais, sem, contudo, apresentar uma política concreta para a efetivação dos mesmos. 
Já no texto constitucional de 1934, concebido após a Primeira Guerra Mundial, os direitos sociais ganharam mais robustez e proteção, graças à influência do constitucionalismo social emergente na própria Europa:

Uma importante inovação ocorre a partir da Constituição de 1934, que incorpora alguns direitos sociais, referindo-se particularmente ao 'direito à subsistência (art. 113, caput), à assistência aos indigentes (art. 113, inc. 34), e também cria os institutos do mandado de segurança e da ação popular (DIMOULIS, DIMITRI. MARTINS, LEONARDO, 2014, p. 25).

No tocante à Constituição de 1937 (concebida durante o Estado Novo), pouco se alterou em relação aos direitos fundamentais individuais, preocupando-se o legislador - no caso o ditador - mais com normas no âmbito das relações trabalhistas.

Encerrada a Segunda Guerra, chegou ao fim a ditadura Vargas e, com o novo período de redemocratização, reestabeleceu-se o constitucionalismo social, promulgando-se a Carta Magna de 1946, que trouxe em seu texto algumas disposições de direitos fundamentais (artigos 129 a 144).

Tanto a Constituição de 1967 quanto a Emenda Constitucional $\mathrm{n}^{\text {o. }}$ 01, de 1969 (que a revisou e a editou quase que por completo), concebidas sob égide de um governo militar, trouxeram em seu bojo alguns dispositivos que configuraram verdadeiro retrocesso para os direitos civis e políticos, sem, contudo, interferir significativamente nos direitos sociais trabalhistas.

A atual Constituição da República (1998) destaca-se pelo tratamento privilegiado conferido aos direitos fundamentais, positivandoos logo em seus artigos iniciais, considerando-os como cláusulas pétreas, sem falar dos inúmeros instrumentos jurídicos processuais de proteção contra o abuso do poder estatal previstos em sua redação pelo legislador constituinte.

Nota-se no texto constitucional brasileiro em comento a inexistência de qualquer tipo de discriminação a direitos dessa natureza, o legis- 
lador conferiu um tratamento isonômico, conferindo a todos a mesma proteção "Com efeito, verifica-se que a Constituição de 1988 tratou de forma isonômica todos os direitos fundamentais por ela consagrados, não criando mecanismos específico para proteção judicial de apenas determinado grupo de direitos fundamentais" (SARLET, 2015, p. 115).

Virgilio Afonso da Silva (2014, p. 25) lembra que, ao contrário de algumas Constituições vigentes em países da Europa, como as de Portugal, Espanha e Alemanha, a Carta brasileira não previu qualquer tipo de regulamentação ou restrição aos direitos fundamentais:

Ao contrário do que ocorre com a constituição brasileira, que não disciplina a possibilidade de restrições e regulamentações a direitos fundamentais, há no direito estrangeiro uma grande quantidade de exemplo de constituições que, além de se referirem expressamente a possibilidades de restrições nesse âmbito, também preveem, de forma expressa, uma necessária garantia a um conteúdo essencial dos direitos fundamentais.

Como se constata, a lei maior - talvez em função da terrível experiência vivenciada pela população brasileira no período ditatorial - privilegiou, de maneira nunca antes vista, a proteção aos direitos fundamentais, configurando-os, praticamente, como base imutável de todo o ordenamento nacional.

Apresentados os principais fatos da História que marcaram a evolução, o desenvolvimento e o interesse pela proteção dessa modalidade normativa junto aos ordenamentos jurídicos dos países democráticos, torna-se possível, agora, discorrer sobre as suas dimensões.

\section{AS DIMENSÕES DOS DIREITOS FUNDAMENTAIS}

O lema da Revolução Francesa ("liberdade, igualdade e fraternidade”), já mencionado em outra ocasião, serviu de inspiração para Karel Vasak desenvolver a "teoria das gerações dos direitos". 
Segundo o jurista tcheco, naturalizado francês, os direitos fundamentais poderiam ser divididos em três gerações.

Os direitos da primeira geração corresponderiam àqueles denominados "civis e políticos", tendo por fundamento a liberdade:

Os direitos da primeira geração são os direitos da liberdade, os primeiros a constarem do instrumento normativo constitucional, a saber, os direitos civis e políticos, que em grande parte correspondem, por um prisma histórico, aquela fase inaugural do constitucionalismo do Ocidente (BONAVIDES, 2015, p. 577).

Os da segunda geração seriam aqueles que teriam por parâmetro a igualdade, ou seja, os direitos de natureza social, econômica e cultural, bem como, o coletivo e das coletividades:

Estes direitos fundamentais, que embrionária e isoladamente já haviam sido contemplados nas Constituições Francesas de 1793 e 1848, na Constituição brasileira de 1824 e na Constituição alemã de 1849 (que não chegou a entrar efetivamente em vigor), caracterizam-se, ainda hoje, por outorgarem ao indivíduo direitos a prestações estatais, como assistência social, saúde, educação, trabalho, revelando uma transição das liberdades formais abstratas para as liberdades materiais concretas, utilizando-se a formulação preferida na doutrina francesa. É, contudo, no século XX, de modo especial nas Constituições do segundo pós-guerra, que estes novos direitos fundamentais acabaram sendo consagrados em um número significativo de Constituições, além de serem objeto de diversos pactos internacionais (SARLET, 2015 p. 47-48).

Por sua vez, os direitos da terceira geração seriam aqueles vinculados à ideia de fraternidade (solidariedade), tais quais o direito ao desenvolvimento, à paz, ao meio ambiente, à comunicação, à propriedade sobre o patrimônio comum da humanidade. 
Ingo Sarlet (2015, p. 49) ressalva que uma das características mais marcantes dessa geração de direitos reside na sua "titularidade coletiva, muitas vezes indefinidas e indeterminável, o que se revela a título de exemplo, especialmente no direito ao meio ambiente, a qualidade de vida (...)".

Alguns juristas, entre os quais pode-se destacar Paulo Bonavides (2015, p. 585-586; 606) defendem, ainda, a existência da quarta e quinta gerações (direito à paz) desse tipo de modalidade normativa, aqueles assim considerados direitos à democracia, à informação e ao pluralismo:

A globalização política na esfera da normatividade jurídica introduz os direitos da quarta geração, que, aliás, correspondem a derradeira fase de institucionalização do Estado social.

São direitos da quarta geração o direito à democracia, o direito à informação e o direito ao pluralismo. Deles depende a concretização da sociedade aberta do futuro, em sua dimensão de máxima universalidade, para a qual parece o mundo inclinar-se no plano de todas as relações de convivência.

(...)

Tal elemento de concórdia, aliás, vai além da presente direção, propelido da necessidade de se criar e promulgar aquele novo direito fundamental: o direito à paz enquanto direito de quinta geração.

(...)

$\mathrm{O}$ direito à paz é o direito natural dos povos. Direito que esteve em estado de natureza no contratualismo de Rousseau ou que ficou implícito como um dogma na paz perpétua de Kant.

Contudo, o termo "gerações" vem sendo objeto de inúmeras críticas pela doutrina, pois, segundo muitos autores, poderia levar à incorreta ideia de substituição gradativa, de uma geração por outra, daí Sarlet (2015, p. 45) sugerir a sua substituição pela expressão dimensões:

Com efeito, não há como negar que o reconhecimento progressivo de novos direitos fundamentais tem o cará- 
ter de um processo cumulativo, de complementaridade, e não de alternância, de tal sorte que o uso da expressão 'gerações' pode ensejar a falsa impressão da substituição gradativa de uma geração por outra, razão pela qual há quem preferia o termo 'dimensões dos direitos fundamentais, posição esta que aqui optamos por perfilhar, na esteira da mais moderna doutrina.

Na mesma linha crítica, defendendo o uso do termo "dimensão" encontra-se George Marmelstein (2016, p. 55-56):

A expressão geração de direitos tem sofrido várias críticas da doutrina nacional e estrangeira, pois o uso do termo geração pode dar a falsa impressão da substituição gradativa de uma geração para outra, o que é um erro, já que, por exemplo, os direitos de liberdade não desaparecem ou não deveriam desaparecer quando surgem os direitos sociais e assim por diante.

Além disso, a expressão pode induzir a ideia de que o reconhecimento de uma nova geração somente pode ou deve ocorrer quando a geração anterior já estiver madura o suficiente. Isso, obviamente, dificulta bastante o reconhecimento de novos direitos, sobre em países ditos periféricos (em desenvolvimento) onde sequer se conseguiu um nível minimamente satisfatório de maturidade dos direitos da chamada 'primeira geração'.

Em razão de todas dessas críticas, a doutrina tem preferido o termo dimensões no lugar de gerações, afastando a equivocada ideia de sucessão, em que uma geração substituía a outra.

Diante das lições doutrinárias mencionadas, se utilizará, doravante, a expressão "dimensão" ao invés de "geração".

Tecidas as considerações mencionadas, cumpre informar que, para os fins deste arrazoado, interessam os direitos da terceira dimensão, de natureza transindividual (difuso ou coletivo). 
A natureza transindividual dos direitos difusos e coletivos e as suas implicações jurídicas quanto à titularidade e às formas de defesa dos interesses de seus titulares

Conforme já visto, os direitos difusos e coletivos são considerados "direitos fundamentais da terceira dimensão" (direito à paz, ao meio ambiente saudável, à propriedade sobre o patrimônio comum da humanidade, à comunicação) e, portanto:

(...) diferentemente das categorias anteriores, sua defesa não se expressa pela tutela do direito de liberdade de um indivíduo em face de seu respectivo Estado, ou pela implementação dos direitos de uma determinada categoria desfavorecida. Aqui, já se trata de defender os direitos de toda humanidade, de modo que os Estados devem respeitá-los independentemente da existência de vínculo de nacionalidade com seus titulares (neste aspecto, estes podem ser considerados 'cidadãos do mundo', e não de um determinado país) e, de eles se encontrarem ou não em seu território. Aliás, por humanidade compreende-se, até mesmo, as gerações futuras, os seres humanos que ainda não nasceram ou sequer foram concebidos (ANDRADE, A.; MASSON; ANDRADE, L., 2017, p. 4).

Um dos principais traços característicos dessa modalidade de direitos - senão, o mais importante - que os distinguem das dimensões anteriores, é a sua natureza transindividual.

Esses direitos transindividuais, também designados "direitos coletivos em sentido amplo" foram previstos, conceituados e classificados pelo legislador brasileiro, no artigo 81, da Lei nº . 8.009/90 (Código de Defesa do Consumidor), em três grandes grupos: i) direitos coletivos em sentido estrito; ii) direitos difusos e iii) direitos individuais homogêneos.

Pelo dispositivo legal mencionado, consideram-se "coletivos em sentido estrito" aqueles direitos de natureza individual, indivisível, mas comuns a certa classe, categoria ou grupo de pessoas determináveis, ora reunidos pela mesma relação jurídica: 
Os interesses coletivos são aqueles também de natureza indivisível, comuns a um grupo, classe ou categoria de indivíduos, reunidos pela mesma relação jurídica básica (como os indivíduos que assinam um contrato de adesão com cláusula abusiva - abusividade da cláusula é compartilhada em igual medida por todos os integrantes do grupo (MAZZILLI, 2014, p. 29).

Por difusos, entende-se aqueles direitos que têm por característica a indeterminação dos sujeitos, a indivisibilidade do objeto, intensa conflituosidade, duração efêmera e contingencial:

(...) interesses metaindividuais, que não tendo atingido o grau de agregação e organização necessário à sua afetação institucional junto à certas entidades ou órgãos representativos dos interesses já socialmente definidos, restam em estado fluido, dispersos pela sociedade civil como um todo (v.g. o interesse à pureza do ar (...) podendo, por vezes, concernir a certas coletividades de conteúdo numérico indefinido (v.g. consumidores). Caracterizam-se pela indeterminação dos sujeitos, pela indivisibilidade do objeto, por sua intensa litigiosidade interna e por sua tendência à transição ou mutação no tempo e no espaço (MANCUSO, 2013, p. 153).

Os individuais homogêneos são direitos subjetivos com um traço de identidade, de homogeneidade, na sua origem, não havendo qualquer impedimento que o seu titular busque individualmente a tutela para a garantia do mesmo:

Os direitos individuais homogêneos, como sua própria definição legal indica, nada mais são do que direitos subjetivos individuais com um traço de identidade, de homogeneidade, na sua origem.

Em sendo simples direitos individuais, nada obsta que seus titulares, caso prefiram, busquem individualmente sua tutela judicial (ANDRADE, A.; MASSON; ANDRADE, L., 2017, p. 28). 
Cumpre lembrar que o fenômeno do transindividualismo ganhou contornos jurídicos somente a partir do final do século XX, com o crescimento da população e a massificação do consumo; circunstâncias sociais que implicaram na exponencial ampliação dos interesses e da titularidade de direitos até, então, considerados exclusivamente individuais (subjetivos).

Assim, inúmeros grupos, classes ou categorias de pessoas - algumas indeterminadas - passaram a ser titulares de interesses e direitos, muitas vezes indivisíveis, daí o uso da expressão direito "metaindividual", "supraindividual" ou "transindividual":

Impende salientar (...) que a doutrina tem sustentado que os direitos transindividuais não pertencem a ninguém de forma isolada. Em tese eles transcendem o indivíduo e são conhecidos como direitos metaindividuais na medida em que atendem a direitos que estão 'além do indivíduo’ ou, ainda, que são supra-individuais, pois se encontram 'acima do indivíduo isoladamente considerado’ (RICHARD PAE KIM, 2012, p. 15).

Por transindividual, Hugo Mazzili (2014, p. 28) ensina que podem ser considerados aqueles direitos ou interesses cujos titulares (grupos, classes ou categorias de pessoas) são de difícil identificação ou nem mesmo podem ser identificados:

Os interesses transindividuais são aqueles que reúnem grupos, classes, ou categorias de pessoas, como são os moradores de uma região no que diga respeito a uma questão ambiental; os consumidores do mesmo produto; os trabalhadores da mesma fábrica; os alunos do mesmo estabelecimento de ensino.

Como se constata pela leitura dos conceitos transcritos alhures, um dos principais problemas decorrentes dessa característica (transindividualismo) encontra-se na titularidade desse direito, uma vez que nem sempre é facil identificar o seu titular, como ocorre, por exemplo, 
nos casos de risco ou dano ambiental ou, ainda, de lesão ao patrimônio público decorrentes dos atos de improbidade administrativa, onde o prejúizo é partilhado por toda a coletividade.

Ou seja, esses tipos de direitos fundamentais transcendem, ultrapassam o direito subjetivo do indivíduo e, verdadeiramente, não pertencem a alguém de forma específica.

Diante desta observação, alguns autores, como Richard Pae Kim (2012, p. 19-20), defendem que o titular não seria um único, mas todos os cidadãos:

Discordando daqueles que entendem que no caso dos direitos transindividuais, em especial, no caso dos direitos difusos os titulares dos direitos, no nosso entender, não há dúvida de que os titulares são todos os cidadãos componentes da sociedade. Aliás, o titular dos direitos individuais são sempre os cidadãos, que sofrerão as consequências da violação a esses direitos coletivos e difusos.

Em razão desse fato (impossibilidade de identificação clara e precisa do titular), surge, originalmente, para o Estado, uma obrigação geral de proteção (correspondente ao status positivo de Jellinek ${ }^{1}$ ) desses cidadãos que, diga-se de passagem, poderá ocorrer de forma normativa ou procedimental:

Além da clássica função dos direitos fundamentais como mecanismo de defesa do indivíduo em face das intervenções do Estado - ou seja, a abstenção estatal -, as disposições de direitos fundamentais muitas vezes abrigam normas que demandam de prestações positivas por parte do poder público. Esses direitos ações estatais positivas, também chamados de direitos a prestações em sentido amplo, são necessários para a satisfação dos direitos fun-

\footnotetext{
Segundo Georg Jellinek, o status positivo consistiria na possibilidade de o indivíduo exigir atuações positivas do Estado em seu favor.
} 
damentais que exigem uma postura ativa do Estado, isto é, que algo seja provido pelo poder público. Os direitos a prestação sem sentido amplo não abrangem somente as prestações fáticas (...), incluindo prestações normativas (consistente na produção de leis) ou na criação de normas organizadoras e procedimentais (FAUSTO KOZO MATSUMOTO KOSAKA, 2012, p. 303-304).

Esse direito de prestação estatal (proteção) outorgado constitucionalmente aos cidadãos, encontrado, por exemplo, nos artigos $5^{\circ}$., XXXII (proteção ao consumidor), 24, XIV (proteção e integração social das pessoas portadoras de deficiência), XV (proteção à infância e juventude) e 225 (proteção ao meio ambiente), tem por principal fundamento, além da própria hipossuficiência dos indivíduos que compõem aquela coletividade, os princípios da "precaução" e "prevenção":

O princípio da prevenção transporta a ideia de um conhecimento completo sobre os efeitos de determinada técnica e, em razão do potencial lesivo já diagnosticado, o comando normativo toma o rumo para evitar tais danos já conhecidos.

(...)

O princípio da precaução (...) tem um horizonte mais abrangente, pois objetiva regular o uso de técnicas sob as quais não há um domínio seguro de seus efeitos, como se sustenta, por exemplo, no tocante a organismos geneticamente modificados, a determinadas substâncias químicas e às radiações eletromagnéticas no uso de telefones celulares (SARLET e FENSTERSEIFER, 2017, p. 209-210).

Portanto, seja por meio da criação de leis, como o Código de Defesa do Consumidor (Lei n ${ }^{\circ}$. 8.009/90); o Estatuto da Criança e do Adolescente (Lei $n^{\circ}$. 8.069/90) e, mais recentemente, o Estatuto da Pessoa com Deficiência (Lei n ${ }^{\circ}$. 13.146/15) ou por intermédio de representação judicial - como ocorre na ação civil pública (Lei no. 7.374/85) - o Estado realiza o seu dever de proteção (normativa ou de procedimento) para os cidadãos titulares desses direitos transindividuais. 
Caso não houvesse essa obrigação estatal, se tornaria muito difícil exercitar, de forma individualizada, a defesa de tais interesses, pois não se conseguiria evitar a insegurança jurídica decorrente de inúmeras decisões judiciais sobre o mesmo fato lesivo, daí a importância de se buscar a tutela judicial de forma coletiva:

Para o sistema judicial, tratar destas questões individualmente, como átomos de um gigantesco universo, representa duplo prejuízo. Primeiro, por ter que enfrentar diversas vezes - com todo o custo inerente - problemas de solução idêntica ou semelhante. E, segundo, por propiciar, no mais das vezes, decisões individuais total ou parcialmente contraditórias, tratando, portanto, indivíduos em situações idênticas ou semelhantes de modo distinto.

Para maximizar a atividade judicial e evitar riscos dantes descritos, a técnica processual coletiva entra em ação, permitindo que estas demandas individuais repetitivas recebam, de uma só vez, tratamento coletivo. Assim, conflitos passam a ser tratados molecularmente, e não mais atomicamente como no processo individual (GAJARDONI, 2012, p. 19).

Contudo, não se pode esquecer que, em razão de o legislador brasileiro ter adotado um "sistema de legitimidade ativa misto" para as chamadas "demandas coletivas" (ação civil pública, ${ }^{3}$ ação popular, ${ }^{4}$ mandado de segurança coletivo ${ }^{5}$ ), além do Estado - por meio do Ministério Público -, outras instituições como partidos políticos, organizações sindicais, ${ }^{6}$ entidades de classes ou associações legalmente constituídas (em funcionamento há mais de um ano) poderão ingressar com ações judiciais para defender os interesses da coletividade que representam.

\footnotetext{
2 Artigo $5^{\circ}$., LXX, LXIII, da CF; artigo 82, da Lei nº. 8.070/90 etc.

3 Lei $\mathrm{n}^{\circ} .7 .347 / 85$.

4 Artigo $5^{\circ}$., LXXIII, da CF; Lei $n^{\circ}$. 4.717/65 alterada pela Lei $n^{\circ}$. 6.513/77.

5 Artigo $5^{\circ}$., LXX, da CF e Lei n ${ }^{\circ}$. 12.106/09.

6 Tome-se como exemplo a ação promovida pelo sindicado de determinada categoria para a cobrança do adicional de insalubridade periculosidade (art. 195, § $2^{\circ}$., CLT).
} 
Fato é que, em decorrência do desenvolvimento tecnológico e das grandes transformações sociais que se apresentam no horizonte, a tendência é que a defesa dos interesses difusos coletivos se intensifique; seja por meio da criação de novos institutos legais ou de ferramentas processuais, daí a importância do jurista aprofundar-se no assunto para enfrentar esse novo cenário gerado pela assimilação, cada vez maior, dos direitos fundamentais da terceira dimensão.

\section{ConsideraÇões Finais}

Por meio da pesquisa doutrinária realizada neste trabalho, ou seja, analisando-se a evolução histórica, os conceitos, os objetivos, as funções e as dimensões, foi possível identificar a principal característica dos "direitos fundamentais difusos e coletivos"; aquela que, diga-se de passagem, os distingue dos demais, qual seja, a transindividualidade e algumas de suas implicações jurídicas para a sociedade.

No entanto, sem a efetiva participação do Estado, por intermédio de prestações (normativas ou procedimentais), dos partidos políticos, ou dos órgãos de representação de classe (associações e sindicados), a defesa desses interesses não se faria possível e, por conseguinte, essa espécie normativa, devidamente positivada no texto constitucional, não passaria de letra morta, sem qualquer efetividade para a sociedade.

Logicamente, não foi o objetivo deste trabalho trazer novas definições ou pontos de vista distintos daqueles já consolidados pela doutrina, mas apenas contribuir com as discussões existentes sobre o tema, já que em decorrência das grandes transformações sociais que despontam no horizonte, torna-se imprescindível - muito mais do que garantir as existentes - desenvolver novas ferramentas jurídicas para se resguardar os direitos e oferecer, como resultado, segurança jurídica aos cidadãos brasileiros.

\section{REFERÊNCIAS}

ALEXY, Robert. Teoria dos direitos fundamentais, 2. ed. $3^{\text {a }}$. Tiragem. São Paulo: Malheiros, 2017. 
ANDRADE, Adriano; MASSON Cleber; ANDRADE, Landolfo. Interesses Difusos e Coletivos. São Paulo: Forense, 2017.

BONAVIDES, Paulo. Curso de direito constitucional, 31. ed. São Paulo: Malheiros, 2017.

CANOTILHO, J. J. Gomes. Direito constitucional e teoria da constituição, 5. ed. Coimbra: Almedina, 2002.

DIMOULIS, DIMITRI. MARTINS, LEONARDO. Teoria geral dos direitos fundamentais, 5. ed. São Paulo: Atlas, 2014.

FERRAJOLI, Luigi. Los fundamentos de los derechos fundamentales, 4. ed. Madri: Trota, 2009.

GAJARDONI, Fernando da Fonseca. Direitos Difusos e Coletivos I: teoria geral do processo coletivo. São Paulo: Saraiva, 2012.

HESSE, Konrad. Temas fundamentais do direito constitucional. São Paulo: Saraiva, 2013.

KIM, Richard Pae. Titularidade dos direitos fundamentais difusos e coletivos (p. 11-24). In: I - KIM, Richard Pae; II - BARROS, Sérgio Resende de; III KOSSAKA, Fausto Kozo Matsumoto (Orgs.). Direitos fundamentais coletivos e difusos: Questões sobre fundamentalidade. São Paulo: Verbatim, 2012.

KOSAKA, Fausto Kozo Matsumoto. O princípio da precaução e o direito difuso à proteção da vida, da saúde e da segurança do consumidor (p. 302-334). In: I - KIM, Richard Pae; II - BARROS, Sérgio Resende de; III - KOSSAKA, Fausto Kozo Matsumoto (Orgs.). Direitos fundamentais coletivos e difusos: Questões sobre fundamentalidade. São Paulo: Verbatim, 2012.

MANCUSO, Rodolfo Camargo. Interesses difusos: Conceito e legitimação para agir, 8. ed. São Paulo: Revista dos Tribunais, 2013.

MARMELSTEIN, George. Curso de direitos fundamentais, 6. ed. São Paulo: Atlas, 2016.

MARTINS, Sérgio Pinto. Direito do trabalho, 23. ed. São Paulo: Atlas, 2007.

MAZZILLI, Hugo Nigro. Tutela dos interesses difusos e coletivos, 7. ed. São Paulo: Saraiva, 2014. 
MIRANDA, Jorge. Teoria do Estado e da Constituição, 4. ed. Rio de Janeiro: Forense, 2015.

MUNIZ, Mirela Karen de Carvalho Bifano. O direito fundamental ao salário mínimo digno: Uma análise à luzo do princípio da dignidade da pessoa humana.

NOVAIS. Jorge Reis. A dignidade da pessoa humana: Dignidade e direitos fundamentais. Vol. 1. Coimbra: Almedina, 2015.

SARLET. Ingo Wolfgang. A Eficácia dos direitos fundamentais: Uma teoria geral dos direitos fundamentais na perspectiva constitucional, 12. ed. $2^{\mathrm{a}}$. Tiragem. Porto Alegre: Livraria do Advogado Editora, 2015.

. FENSTERSEIFER, Tiago. Princípios do direito ambiental, 2. ed. São Paulo: Saraiva, 2017.

SILVA, José Afonso. Curso de direito constitucional positivo, 35. ed. São Paulo: Malheiros, 2012.

SILVA, Virgílio Afonso. Direitos fundamentais, 2. ed. $4^{\mathrm{a}}$. Tiragem. São Paulo: Malheiros, 2017.

\section{Sobre o autor}

Washington Eduardo Perozim da Silva

Bacharel em Ciências Jurídicas e Sociais pela Pontifícia Universidade Católica de Campinas/Puccamp. Advogado. Especialista em Gestão Estratégica de Negócios pela Faculdade de Campinas/Facamp. Especialista em Direito Tributário pela Escola Paulista de Direito/EPD. Mestrando em Direito - Universidade Metodista de Piracicaba/Unimep - Piracicaba/SP - Professor de Direito Civil e Direito Empresarial na Devry/Metrocamp.

E-mail: washington@perozim.com.br

Submetido em: 26-7-2017

Aceito em: 30-10-2017 